\title{
Primary lung carcinoma after heart or lung transplantation: Management and outcome
}
A. C. Anyanwu, FRCS
E. R. Townsend, FRCS
N. R. Banner, FRCP
M. Burke, FRCPath
A. Khaghani, FRCS
M. H. Yacoub, FRCS

Objective: We sought to examine our management and outcome of lung carcinoma occurring after thoracic organ transplantation.

Methods: We performed a retrospective review of cases of primary lung carcinoma diagnosed between 1990 and 2000 in patients who have previously undergone thoracic transplantation at our institution.

Results: Seventeen patients were identified (1 lung and 16 heart transplants). Median time from transplantation to diagnosis of lung carcinoma was 89 months (range, 46-138 months). Predominant presentation was as an incidental finding at chest radiography (13/17). All patients had smoked cigarettes before transplantation, with 5 continuing to smoke after transplantation. Histologic types were squamous $(\mathrm{n}=11)$, adenocarcinoma $(\mathrm{n}=3)$, small cell $(\mathrm{n}=2)$, and undifferentiated $(\mathrm{n}=1)$. Revised International Union Against Cancer (UICC) clinical stage at the time of diagnosis was stage I or II in 11 of 17 patients. Of these, 9 underwent surgical resection; 2 patients unfit for surgical intervention had radiotherapy. Surgical procedures were lobectomy $(\mathrm{n}=5)$, wedge excision $(\mathrm{n}=3)$, and no resection $(\mathrm{n}=1)$. Median survival after diagnosis was 12 months for all patients and 24 months if the tumor was resected. Six patients who had surgical resection subsequently died (survival of 2, 9, 21, 21, 36, and 67 months); 2 remain alive after 12 and 54 months, respectively.

Conclusions: When possible, surgical intervention should be undertaken for early stage lung cancer occurring after thoracic transplantation because medium-term survival is achievable. Sublobar excisions and definitive radiotherapy should be considered if comorbidity prevents optimal surgical treatment. \footnotetext{
Unit, Royal Brompton and Harefield NHS Trust, Harefield Hospital, Uxbridge, Middlesex, United Kingdom.

Read at the Eighty-first Annual Meeting of The American Association for Thoracic Surgery, San Diego, Calif, May 6-9, 2001.

Received for publication May 14, 2001; revisions requested July 10, 2001; revisions received Aug 8, 2001; accepted for publication Aug 31, 2001.

Address for reprints: E. R. Townsend, Consultant Thoracic Surgeon, Harefield Hospital, Uxbridge, Middlesex UB9 6JH, United Kingdom (E-mail: e.townsend@rbh. nthames.nhs.uk).

J Thorac Cardiovasc Surg 2002;124:1190-7

Copyright () 2002 by The American Association for Thoracic Surgery

$0022-5223 / 2002 \$ 35.00+0 \quad \mathbf{1 2 / 6 / 1 2 4 8 8 5}$

doi: $10.1067 / \mathrm{mtc} .2002 .124885$
}

From the Thoracic Surgery and Transplant

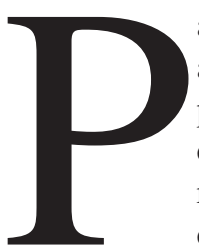

atients who have undergone solid organ transplants are known to have an increased risk of neoplasia compared with that of the general population. Prognosis of most solid organ tumors occurring in this context is poor, and neoplasia remains the most frequent non-graftrelated cause of late deaths after heart transplantation. ${ }^{1}$ Primary bronchogenic carcinoma has a particularly poor prognosis in the nontransplant setting and is the leading cause of cancer death in men and the third leading cause in women in England and Wales. ${ }^{2}$ The main predisposing factor, cigarette smoking, is also a predisposing factor for end-stage cardiopulmonary disease. Many recipients of thoracic transplants are therefore at high risk of bronchogenic carcinoma. In this article we present a series of 17 thoracic transplant recipients who have been given a diagnosis of lung cancer at our institution over a 10-year period.

\section{Materials and Methods}

Between 1981 and 1999, we performed 2335 thoracic transplantations at our institution. All patients are followed up on an annual basis or more frequently if clinically indicated. 
TABLE 1. Clinical characteristics

\begin{tabular}{|c|c|c|c|c|c|c|}
\hline $\begin{array}{l}\text { Case } \\
\text { no. }\end{array}$ & Sex & $\begin{array}{c}\text { Age at } \\
\text { transplantation }(y)\end{array}$ & Diagnosis & $\begin{array}{l}\text { Smoking history } \\
\text { at transplantation }\end{array}$ & $\begin{array}{c}\text { Known smoker } \\
\text { after transplantation }\end{array}$ & $\begin{array}{l}\text { Interval from transplantation to } \\
\text { diagnosis }(\mathrm{mo})\end{array}$ \\
\hline $1^{*}$ & $M$ & 50 & Ischemic & Exsmoker & No & 100 \\
\hline 2 & $M$ & 67 & Ischemic & Exsmoker & Yes & 46 \\
\hline 3 & $M$ & 48 & Ischemic & Still smoking & No & 107 \\
\hline 4 & M & 61 & DCM & Still smoking & Yes & 107 \\
\hline 5 & $M$ & 63 & Ischemic & Still smoking & Yes & 86 \\
\hline 6 & M & 50 & Ischemic & Exsmoker & No & 89 \\
\hline 7 & $M$ & 49 & Ischemic & Exsmoker & No & 101 \\
\hline 8 & $M$ & 46 & Ischemic & Still smoking & No & 48 \\
\hline 9 & M & 49 & Ischemic & Exsmoker & No & 133 \\
\hline 10 & M & 54 & DCM & Exsmoker & No & 53 \\
\hline 11 & $M$ & 67 & Ischemic & Exsmoker & No & 83 \\
\hline 12 & $M$ & 52 & Ischemic & Exsmoker & No & 132 \\
\hline $13 t$ & M & 39 & A1A & Exsmoker & No & 59 \\
\hline 14 & $M$ & 59 & Ischemic & Exsmoker & No & 136 \\
\hline 15 & $\mathrm{~F}$ & 55 & Ischemic & Exsmoker & No & 138 \\
\hline 16 & $M$ & 52 & DCM & Still smoking & Yes & 84 \\
\hline 17 & M & 58 & Ischemic & Exsmoker & No & 89 \\
\hline
\end{tabular}

Ischemic, Ischemic cardiomyopathy; DCM, dilated cardiomyopathy; A1A, Alpha-1 antitrypsin deficiency.

*Heterotopic heart transplant.

tSingle-lung transplant with carcinoma in contralateral lung.

Follow-up evaluation includes (inter alia) a chest examination and chest radiography. Any patients with unexplained respiratory symptoms or unexplained shadows on chest radiography are investigated by means of bronchoscopy and computed tomographic (CT) scanning to exclude lung carcinoma.

Where lung carcinoma was diagnosed, decisions on further treatment were undertaken jointly by a multidisciplinary team consisting of thoracic surgeons, chest physicians, medical oncologists, radiotherapists, radiologists, and transplant physicians. Decisions on patient management were individualized and depended on clinical staging and the patient's overall clinical condition. Surgical operations were undertaken by one of 3 surgeons, with the choice of procedure being left to the individual surgeon's discretion. After surgical intervention, a preoperative immunosuppressive regimen was continued, with drugs administered orally by means of a nasogastric tube if the patient was unable to take oral medication or by means of the intravenous route if gut absorption was poor. Cyclosporine (INN: ciclosporin) levels were monitored daily. No additional steroids were given in the postoperative period. After diagnosis of lung carcinoma, patients were followed up on a 3-month basis to assess for clinical or radiologic signs of local recurrence or distant metastasis. No patients were lost to follow-up after diagnosis of lung carcinoma.

\section{Data Collection}

All transplant recipients who were given a diagnosis of primary lung carcinoma between 1991 and 2000 were identified by means of review of patient and pathologic databases. Patients with secondary lung tumors, lymphomas, and sarcomas were not included in this series. Additionally, patients in whom bronchoalveolar cell carcinoma was the indication for transplantation were excluded. Data were obtained on the basis of a retrospective review of pathologic records and medical case notes.

\section{Statistical Analysis}

Survival analysis was performed by using the life-table method. Survival was defined as freedom from death from any cause.

\section{Results}

\section{Patients}

Seventeen patients were identified: 16 had undergone heart transplantation, and 1 had undergone lung transplantation (single-lung transplantation with carcinoma in the contralateral lung). The demographic characteristics of these patients are shown in Table 1. The median age at the time of diagnosis of lung carcinoma was 60 years (range, 44-71 years). All but one patient was aged 50 years or older at the time of diagnosis. Lung carcinoma was diagnosed at a median of 89 months ( 7.4 years) after transplantation, with a range of 46 to 138 months. All patients had received triple-therapy immunosuppression with cyclosporine, prednisolone, and azathioprine, with early withdrawal of prednisolone. Seven patients had received induction therapy with antithymocyte globulin.

Most patients (13/17) were asymptomatic at presentation and presented with an incidental abnormality noted on chest radiography. In only one patient did retrospective review of previous radiographs show a missed lesion. Presenting symptoms in the other 4 patients were shortness of breath $(\mathrm{n}=1)$, cough $(\mathrm{n}=1)$, pain $(\mathrm{n}=1)$, and neck mass $(\mathrm{n}=$ 1). Definitive (histologic) diagnosis was made at bronchoscopy (6/17), CT biopsy (4/17), mediastinoscopy (1/17), thoracotomy or thoracoscopy (5/17), and cervical lymph node biopsy (1/17). 
TABLE 2. Staging, treatment, and outcome

\begin{tabular}{|c|c|c|c|c|c|c|c|c|}
\hline Patient no. & T2 NO Mo & UICC & Symptoms & Site & Cell type & Treatment & Status & $\begin{array}{l}\text { Survival } \\
\text { (d) }\end{array}$ \\
\hline 1 & T2 NO MO & I & No & RUL & Squamous & Surgery & Dead & 663 \\
\hline 2 & T2 N2 M1 & IV & Yes & RUL & Squamous & RT & Dead & 39 \\
\hline 3 & T1 No M0 & I & No & LLL & Squamous & Surgery & Dead & 1007 \\
\hline 4 & T1 No MO & I & No & LUL & Squamous & $\mathrm{RT}^{*}$ & Dead & 122 \\
\hline 5 & T2 NO MO & i & No & RUL & Adeno & Surgery & Dead & 2040 \\
\hline 6 & T2 NO MO & I & No & LUL & Adeno & Surgery & Dead & 658 \\
\hline 7 & T2 N1 M0 & II & No & RML & Squamous & Surgery & Dead & 344 \\
\hline 8 & T2 NO MO & I & No & RUL & Squamous & Surgery & Alive & $1608 \ddagger$ \\
\hline 9 & T4 N3 MO & III & Yes & LUL & Small Cell & Chemo, RT & Dead & 30 \\
\hline 10 & T4 N2 M1 & IV & No & RUL & Undifferentiated & Chemo & Dead & 269 \\
\hline 11 & T3 N1 M1 & IV & Yes & RML & Small Cell & Chemo & Dead & 188 \\
\hline 12 & T2 N1 MO & II & No & RUL & Squamous & Chemo, RT† & Dead & 300 \\
\hline 13 & T2 N2 M0 & III & No & RLL & Squamous & RT & Dead & 199 \\
\hline 14 & T2 NO MO & I & Yes & LLL & Adeno & Surgery & Dead & 65 \\
\hline 15 & T2 NO MO & I & No & RUL & Squamous & $\mathrm{RT}^{*}$ & Alive & $461 \ddagger$ \\
\hline 16 & T1 NO MO & 1 & No & RUL & Squamous & Surgery & Alive & $375 \ddagger$ \\
\hline 17 & T2 N2 M0 & III & No & RUL & Squamous & RT & Dead & 336 \\
\hline
\end{tabular}

RUL/RML/RLL, Right upper/middle/lower lobe; RT, radiotherapy; LUL/LLL, left upper/lower lobe; Adeno, adenocarcinoma; Chemo, chemotherapy. *Unfit for lung resection surgery.

†Thoracotomy or lobectomy not feasible (unfit for pneumonectomy).

‡Censored follow-up.

\section{Staging and Pathology}

All patients underwent pretreatment staging by means of a CT scan. In addition, some patients underwent bronchoscopy (16/17), mediastinoscopy (6/17), positron emission tomography (2/17), and thoracoscopy (2/17). Table 2 shows the clinical stage at the time of diagnosis. Staging was based on the revised international American Joint Commission for Cancer/International Union Against Cancer (AJCC/UICC) system. ${ }^{3}$ Eleven patients had stage I or stage II disease at the time of diagnosis. There was no correlation between the presence of symptoms and clinical stage, with the majority presenting as incidental radiographic findings, regardless of clinical stage. Histologic classification is shown in Table 2.

\section{Management}

The 6 patients who had advanced disease (stage III or IV) were treated with chemotherapy, palliative radiotherapy, or a combination of both. The remaining patients were considered for surgical resection. Two patients with surgically resectable disease were unsuitable candidates, one because of poor respiratory reserve and another because of heart failure as a result of transplant coronary artery disease. These 2 patients received radiotherapy (one palliative and one definitive). The remaining 9 patients with clinical stage I or II disease proceeded to thoracotomy. Details of surgical procedures performed are shown in Table 3. In one patient a central right upper lobe tumor was found to breach the oblique fissure, requiring a right pneumonectomy for surgical clearance; because the patient was not fit for pneumonectomy and the tumor was not amenable to wedge exci- sion, no resection was performed. Surgical resection was undertaken in 8 patients (Table 3 ). Three patients had sublobar resections. The 3 sublobar excisions were a lingulasparing left upper lobectomy, a wedge excision of a tumor breaching the horizontal fissure (a wedge excision was done in preference to bilobectomy), and a wedge excision of an apical left lower lobe tumor. All sublobar excisions were done because of concerns about respiratory reserve. Pathologic staging led to upstaging in one patient (case 16), in whom N2 paratracheal nodes excised at the time of the operation were positive for carcinoma.

\section{Outcomes}

Figure 1 shows actuarial survival after diagnosis of lung carcinoma. Median survival was 12 months, and 5-year survival was $19 \%$. No patient with stage II, III, or IV disease survived up to a year after diagnosis. The 5-year survival for patients with clinical stage I disease at diagnosis was $35 \%$.

\section{Discussion}

Demographic characteristics of patients who had lung carcinoma in our transplant population were similar to those of the nontransplant lung carcinoma population. As in the nontransplant population, lung carcinoma in the transplant recipient was associated with tobacco smoking, and patients were predominantly in their sixth or seventh decade. Although there is evidence of increased prevalence of most solid tumors in transplant recipients, the association between immunosuppression and lung carcinoma is less cer- 


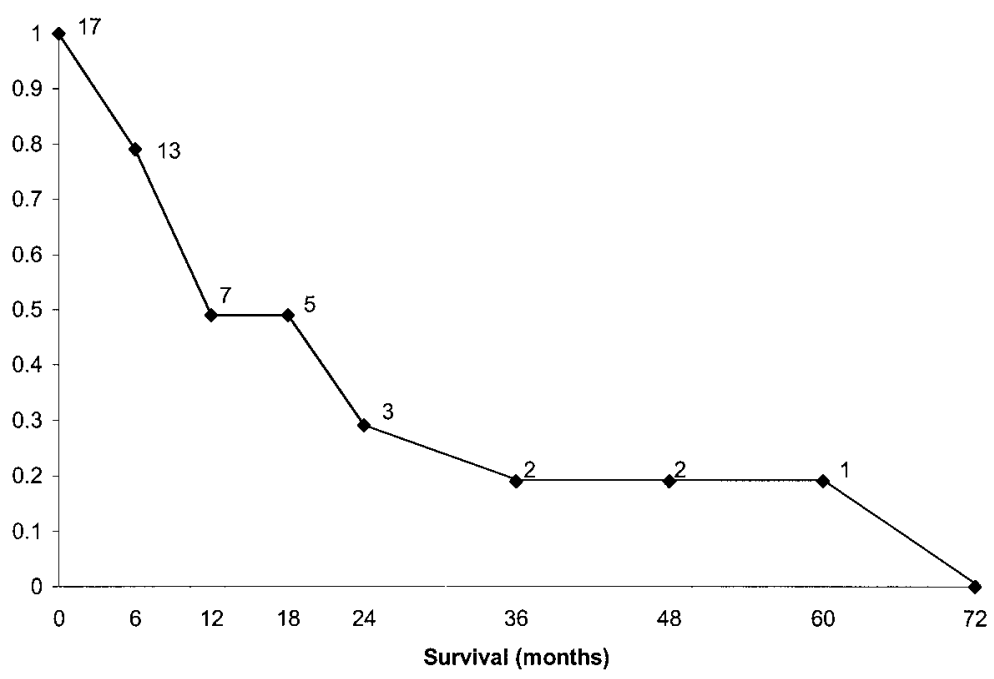

Figure 1. Survival after diagnosis of lung carcinoma $(n=17)$.

TABLE 3. Operations for lung carcinoma in transplant recipients

\begin{tabular}{|c|c|c|c|c|c|c|}
\hline Sex/age (y) & $\begin{array}{l}\text { Stage } \\
\text { pTNM }\end{array}$ & Cell type & Site & Status & $\begin{array}{c}\text { Survival } \\
\text { (mo) }\end{array}$ & Cancer recurrence? \\
\hline \multicolumn{7}{|l|}{ Lobectomies } \\
\hline $\mathrm{M} / 58$ & T2 No & Squamous & RUL & $\begin{array}{c}\text { Dead } \\
\text { (carcinoma) }\end{array}$ & 21 & Bony metastases 14 mo \\
\hline $\mathrm{M} / 70$ & T2 No & Adeno & RUL & $\begin{array}{c}\text { Dead } \\
\text { (cardiac) }\end{array}$ & 67 & No \\
\hline $\mathrm{M} / 58$ & T2 No & Squamous & RML & $\begin{array}{c}\text { Dead } \\
\text { (carcinoma) }\end{array}$ & 9 & $\begin{array}{l}\text { Local recurrence } 9 \text { mo Completion } \\
\text { right pneumonectomy; died of } \\
\text { postoperative infection in left lung }\end{array}$ \\
\hline $\mathrm{M} / 71$ & T2 No & Squamous & LLL & $\begin{array}{l}\text { Dead } \\
\text { (postoperative } \\
\text { respiratory } \\
\text { failure) }\end{array}$ & 2 & Not applicable \\
\hline $\mathrm{M} / 59$ & T1 N2 & Squamous & RUL & Alive & 12 & No \\
\hline \multicolumn{7}{|l|}{ Wedge or segment excisions } \\
\hline $\mathrm{M} / 57$ & T2 NO & Adeno & LUL apex & $\begin{array}{c}\text { Dead } \\
\text { (carcinoma) }\end{array}$ & 21 & Yes \\
\hline $\mathrm{M} / 56$ & T2 NO & Squamous & LLL apex & $\begin{array}{l}\text { Dead (graft } \\
\text { vasculopathy) }\end{array}$ & 36 & No \\
\hline $\mathrm{M} / 50$ & T1 No & Squamous & RML/RUL & Alive & 54 & No \\
\hline
\end{tabular}

RUL/RML/RLL, Right upper/middle/lower lobe; Adeno, adenocarcinoma; LUL/LLL, left upper/lower lobe.

tain. ${ }^{4}$ Although most studies of heart transplant recipients have reported a higher incidence of lung carcinoma in thoracic transplant recipients compared with that in the general population, this is not necessarily because of immunosuppression because heart transplant recipients are a selected group at higher risk of development of lung carcinoma by virtue of previous smoking and more advanced age (half of our heart transplant recipients are older than 50 years).

Several indirect observations from our cohort tend to support the view that immunosuppression is not a primary causative factor in lung carcinoma. We did not experience any lung carcinoma in our young recipients (the youngest patient to have lung carcinoma was 44 years old at the time of diagnosis), despite many of them having received immunosuppression for up to 10 years. Second, we have not observed lung carcinoma in any life-long nonsmoking recipients. Third, we did not observe lung carcinoma in any transplanted lungs. Although we do transplant lungs from donors with a smoking history, most of these tend to be young and carefully selected to exclude smoking-related lung disease. Finally, there was an association between lung 
TABLE 4. Comparisons with other series

\begin{tabular}{|c|c|c|c|c|c|c|c|}
\hline Reference & n & $\begin{array}{l}\text { Smoking } \\
\text { history }\end{array}$ & $\begin{array}{l}\text { Median time from } \\
\text { transplantation to } \\
\text { diagnosis (mo) }\end{array}$ & $\begin{array}{l}\text { Histology: } \\
\text { non-small } \\
\text { cell }\end{array}$ & $\begin{array}{l}\text { Early cancer } \\
\text { (stage I/ II) }\end{array}$ & $\begin{array}{l}\text { Surgical } \\
\text { resection }\end{array}$ & $\begin{array}{c}\text { Median } \\
\text { survival } \\
(\mathrm{mo})\end{array}$ \\
\hline Present study & 17 & All & 84 & $15 / 17$ & $11 / 17$ & 8 & 12 \\
\hline $\begin{array}{l}\text { Pham and colleagues, } \\
\text { 1995, Pittsburgh }{ }^{8}\end{array}$ & 10 & $?$ & 19 & $10 / 10$ & $2 / 10$ & 3 & 1 \\
\hline $\begin{array}{l}\text { Goldstein and colleagues, } \\
\text { 1996, New York }{ }^{5}\end{array}$ & 9 & All & 38 & $5 / 9$ & $1 / 8$ & 0 & 3 \\
\hline $\begin{array}{l}\text { Taniguchi and } \\
\text { colleagues, 1997, } \\
\text { Oklahoma }\end{array}$ & 4 & All & 70 & $3 / 4$ & $1 / 4$ & 3 & 8 \\
\hline $\begin{array}{l}\text { Delcambre and } \\
\text { colleagues, 1996, }^{\text {France }}{ }^{9}\end{array}$ & 4 & All & 63 & $3 / 4$ & $1 / 4$ & 1 & 3 \\
\hline $\begin{array}{l}\text { Flemming and colleagues, } \\
\text { 1994, Missouri10 }\end{array}$ & 3 & All & 12 & $3 / 3$ & $2 / 3$ & 2 & 18 \\
\hline
\end{tabular}

carcinoma and ischemic heart disease: although ischemic heart disease was the indication for heart transplantation in $40 \%$ of patients treated at our center, it was the primary underlying disease in $80 \%$ of those with lung carcinoma. Similar observations were made by Goldstein and colleagues, ${ }^{5}$ who reported a series of 9 patients with lung carcinoma after heart transplantation, of whom 8 had ischemic heart disease (the ninth patient had idiopathic cardiomyopathy but was a smoker, as was the case in the nonischemic patients in our cohort). Whether immunosuppression does increase the risk in patients already predisposed to lung carcinoma is uncertain, but it does not appear to precipitate lung neoplasia in those recipients who are otherwise not at risk.

The predominant presentation was as an incidental finding on chest radiography. It is of note that 6 of 17 patients had advanced disease despite regular follow-up, pointing to the inadequacy of chest radiography as a screening tool for lung carcinoma. ${ }^{6,7}$ Results from other series have shown an even greater prevalence of advanced disease (Table 4).,5,8-10 Preliminary results of screening with low-dose spiral CT scanning ${ }^{11}$ are more promising, and this modality of screening might be considered as an alternative to chest radiography. There might be also a case for performing a lung CT scan as part of assessment for heart transplantation in patients with a history of smoking in a bid to detect occult carcinomas that might later become apparent. ${ }^{5}$ However, in our series the time interval between transplantation and cancer diagnosis in our patients was sufficiently long to suggest that clinically detectable cancers were not missed at assessment. In our series 11 patients had potentially curable disease. However, 2 patients did not undergo surgical intervention because of comorbidity. In one patient with borderline lung function, thoracotomy was undertaken, but no resection was performed because the tumor required a right pneumonectomy for surgical clearance.
Surgical intervention, however, remains the treatment of choice, and where undertaken, medium-term survival was achievable. We undertook successful surgical resection in 8 patients, and this is reflected in a relatively promising median survival (for the entire cohort) of 12 months compared with those of other series, which have reported a median survival of 27 days $^{8}$ and 3 months. ${ }^{5}$ However, optimal surgical treatment might not be possible because of impaired respiratory function. Our observation has been that thoracic transplant recipients do not tolerate extensive lung resection in the same manner as nontransplant recipients. Many patients, by virtue of previous smoking (which has caused end-stage failure of one organ), invariably have a degree of chronic lung damage, even in the presence of normal spirometry.

Additionally, transplant recipients are more prone to major lung infection. Two of our patients died because of postoperative infection in the residual lung. The less the residual lung volume after resection, the more the likelihood that major infection will lead to acute decompensation. We performed one pneumonectomy, a completion pneumonectomy for local recurrence 9 months after complete resection of a T2 tumor by means of lobectomy. This patient died of postoperative respiratory failure precipitated by infection in the remaining lung. Concerns about residual cardiopulmonary function led us to perform 3 sublobar excisions. In 2 of these patients, the ideal anatomic operation for surgical clearance was pneumonectomy. Of the 8 patients who underwent surgical intervention, 1 died in the postoperative period, and 3 subsequently died of local recurrence (one of whom had a wedge excision). The other 4 patients did not show any local recurrence (Table 3), with 3 surviving up to 3 years (of whom 2 had sublobar excisions). When a pneumonectomy or lobectomy cannot be undertaken (as might often be the case in the transplant recipient), a sublobar excision remains a useful option. Definitive radiotherapy 
should be considered in those patients who cannot tolerate any level of surgical resection. One of our patients (who was unsuitable for lung resection) remains alive and free of cancer 15 months after diagnosis after receiving definitive radiotherapy with the continuous, hyperfractionated, accelerated radiotherapy regimen. ${ }^{12}$ Patients with stage I or II disease should therefore not be turned down for curative therapy on the grounds of previous transplantation alone. Surgical intervention did not present any specific technical difficulties related to previous transplantation, except in a right upper lobectomy in a patient whose right lung was densely adherent to a heterotopically placed heart graft. Complete tumor clearance was achieved without compromising the heterotopic heart, and this patient survived 21 months.

Because this is an uncommon clinical problem, our study is necessarily limited by small numbers. Also, our treatments have not been randomly or systematically assigned, being largely dependent on physician preference. However, our findings are in line with those of other published series (Table 4). Our data should help guide other clinicians faced with this uncommon clinical scenario. A high index of suspicion is required in the follow-up of transplant recipients with a history of smoking with a view to detecting cancers at an early stage because this seems to present the only hope for averting what is otherwise a likely dismal outcome. Alternative screening modalities, such as CT scanning and positron emission tomography, might improve detection of early tumors, but their role in this setting is yet undetermined.

\section{References}

1. Hosenpud JD, Bennett LE, Keck BM, Boucek MM, Novick RJ. The Registry of the International Society for Heart and Lung Transplantation: seventeenth official report-2000. J Heart Lung Transplant. 2000;19:909-31.

2. Coleman MP, Babb P, Mayer D, Quinn MJ, Sloggett A. Cancer survival trends in England and Wales, 1971-1995: deprivation and NHS Region. London: Office for National Statistics; 2001

3. Mountain CF. Revisions in the International System for Staging Lung Cancer. Chest. 1997;111:1710-7.

4. Taniguchi S, Cooper DK, Chaffin JS, Zuhdi N. Primary bronchogenic carcinoma in recipients of heart transplants. Transpl Int. 1997;10: 312-6.

5. Goldstein DJ, Austin JH, Zuech N, Williams DL, Stoopler MB, Michler RE, et al. Carcinoma of the lung after heart transplantation. Transplantation. 1996;62:772-5.

6. Strauss GM. Randomized population trials and screening for lung cancer: breaking the cure barrier. Cancer. 2000;89:2399-421.

7. Gavelli G, Giampalma E. Sensitivity and specificity of chest X-ray screening for lung cancer: review article. Cancer. 2000;89(suppl 11): 2453-6.

8. Pham SM, Kormos RL, Landreneau RJ, Kawai A, Gonzalez-Cancel I, Hardesty RL, et al. Solid tumors after heart transplantation: lethality of lung cancer. Ann Thorac Surg. 1995;60:1623-6.

9. Delcambre F, Pruvot FR, Ramon P, Noel C, Pol A, Jaillard-Thery S, et al. Primary bronchogenic carcinoma in transplant recipients. Transplant Proc. 1996;28:2884-5.
10. Fleming RH, Jennison SH, Naunheim KS. Primary bronchogenic carcinoma in the heart transplant recipient. Ann Thorac Surg. 1994; 57:1300-1.

11. Kaneko M, Kusumoto M, Kobayashi T, Moriyama N, Naruke T, Ohmatsu $\mathrm{H}$, et al. Computed tomography screening for lung carcinoma in Japan. Cancer. 2000;89(suppl 11):2485-8.

12. Saunders M, Dische S, Barrett A, Harvey A, Griffiths G, Palmar M. Continuous, hyperfractionated, accelerated radiotherapy (CHART) versus conventional radiotherapy in non-small cell lung cancer: mature data from the randomised multicentre trial. CHART Steering committee. Radiother Oncol. 1999;52:137-48.

\section{Discussion}

Dr Thomas J. Kirby (Cleveland, Ohio). This obviously represents a very unusual group of patients with primary lung carcinoma many years after heart-lung transplantation.

My comments have to do with the title of your article, along with your conclusions. You focus a great deal on the word "epidemiology." It is very difficult to extrapolate any epidemiologic parameters from a group of 17 patients for whom the average time after transplantation or time to diagnosis was 8.5 years after transplantation. In 8.5 years after a heart or a lung transplantation, the transplantation cohort is at least cut in half or two thirds by patient deaths related to side effects of immunosuppression or chronic rejection. Therefore, you would not be able to comment on 2 primary facets in epidemiology of any disease: incidence and prevalence. If your premise is that somehow the incidence and prevalence of lung cancer is different in your study group, then you should compare your group with the control arm: the incidence and prevalence of lung cancer in the normal smoking population.

You mentioned that the immunosuppression received by these patients represented a risk factor, but this cannot be the case, otherwise we would see an increased incidence in lung cancer after liver and kidney transplantations, for example. Therefore, standard immunosuppression is not a causative factor in development of lung carcinoma in your group.

The second point has to do with the management of these patients. I could not tell how you decided to do a wedge resection versus a lobectomy versus a pneumonectomy, and I would like you to comment on your choice of operations.

Not so much in your talk but in your article, you mentioned turning down one patient in whom you said the cancer had crossed the major fissure from the right upper lobe into the middle lobe. Most thoracic surgeons would perform a segmental resection or a wedge resection of the right middle lobe, lower lobe, or both combined with a right upper lobectomy and not deem the patient's condition inoperable.

Having to do with intraoperative staging, you started out preoperatively with 9 patients who you took to the operating room with clinical stage I or II disease. Postoperatively, I did not see you change the stage of any of those patients. Can you comment on how you staged the disease of these patients intraoperatively. If you found N2 or N3 disease intraoperatively, would you still perform resection? Also, what role do you believe mediastinoscopy has in this patient group? Do you really believe that pneumonectomy is an acceptable operation in this group of patients?

Last, you did not mention kidney function in these individuals. Every one of them has impaired kidney function, which obviously predisposes to complications postoperatively. At least $50 \%$ of 
patients will have significant renal dysfunction and azotemia 8 to 10 years after a heart or lung transplant. This is an important factor to consider preoperatively and to closely monitor postoperatively.

Dr Anyanwu. Thank you very much for your questions, Dr Kirby. As regards extrapolating epidemiology, I deliberately did not comment on the incidence or prevalence of lung cancer in this group for the reasons that you described. There are difficulties in analyzing cancers that occur in patients who have had a transplant. Most workers have used actuarial methods to describe freedom from cancer, but as we heard in the article presented 2 days ago by Dr Grunkemeier, there are problems with using actuarial methods to describe nonfatal events. Therefore, it is very difficult in any way to attempt to define the prevalence or incidence of cancer in any transplanted cohort, which is why we have not attempted to do that, and more so, from 17 of over 2000 patients who have undergone transplantation in our institution, half of whom do not survive 10 years, it is very difficult to make any definitive comment on the incidence or prevalence.

As regards the choice of operation, this is generally left up to the surgeon and is determined by the tumor location, as well as the lung reserve. Many of these patients have comorbidity. Several of them, as I said, have gone up to 7 or 8 years after transplantation, and by definition, most of them would have some degree of transplant coronary artery disease. These patients, in our experience, do not tolerate lung resection in the same way as the standard nontransplant patient. We lost 2 patients who had infection in the residual lung to a degree of infection that we would have expected to resolve were they not transplant patients. Therefore, in these patients the more lung you take out, the less there is to cope with infective complications. The 2 patients who had wedge excisions would have required a bilobectomy or pneumonectomy for ideal surgical clearance, which we believed they would not survive on the basis of their lung function and comorbidity. This has not been a bad strategy because 1 of them is still alive after 4 years, and the other died after 3 years with no cancer recurrence.

As regards the role of pneumonectomy, our present practice is that we would be very pushed to perform a pneumonectomy in this patient group. As I said, we performed one completion pneumonectomy, and the left lung could not cope with infection, to which these patients are predisposed. Therefore, we would be very reluctant now to perform a pneumonectomy, which is the reason why we performed an open-and-close thoracotomy in 1 patient who had potentially resectable disease by means of pneumonectomy. That tumor was a central tumor that breached the fissure, and for adequate anatomic clearance, it would have required a pneumonectomy-and that was a right-sided pneumonectomy in a patient in his seventh decade-and there was not adequate pulmonary reserve. The patient was referred to the radiotherapist, who did not believe there was adequate reserve for radical radiotherapy either, and therefore that patient had palliative treatment.

As regards the staging, the staging I have presented was the preoperative staging. One of the patients was found to have N2 disease on pathologic examination, and that was one of the patients who had a lobectomy, and he remains alive after a year.

As for the role of mediastinoscopy, we apply the same practice that we apply to the rest of our patients with cancer, and we perform mediastinoscopy only in those patients with suspicious disease on CT scans, and by suspicious we mean lymph nodes of about $1 \mathrm{~cm}$ or more.

As regards renal function, as you said, most patients have some degree of impaired renal function, and in the patient who had radical radiotherapy for stage II tumor, that was the major consideration because this patient had transplant coronary artery disease and impaired renal function, and we believed that subjecting the patient to a major operation would tip the patient into permanent renal replacement.

Dr Valerie W. Rusch (New York, NY). I think that although the numbers of patients in your series are small, one of the striking findings is the absolutely dismal outcome for patients who had higher than stage I disease. In a way this is similar to what we have seen at our institution, Memorial Sloan-Kettering in New York, and other large cancer centers with respect to patients who have either underlying chronic lymphocytic leukemia or have previously been treated for Hodgkin's disease. In those instances the outcome for patients who have greater than stage I, or in some cases stage II, disease is related to their complete inability to tolerate both chemotherapy and radiation because of poor marrow reserve. Would you comment a bit further on those patients? It certainly does raise the issue that you mentioned briefly, which is the consideration of perhaps more extensive screening in this high-risk population, which you have already defined so well, with a low-dose helical CT scan.

Dr Anyanwu. Unfortunately, I cannot comment directly on the patients who were treated with palliative chemotherapy because most of them were treated at a nearby oncology unit outside of our institution rather than at our institution. Therefore, I cannot really give you details as to what considerations were taken into account in providing them with the treatment.

As regards the screening of this population, in our cohort, because most of the tumors occurred a median of 7 years after transplantation, it is unlikely that any form of preoperative screening would have been of benefit, but in other series there is a suggestion that some of the tumors had predated the transplantation, and I think there might be a role for CT or positron emission tomography scanning in these patients if there is thought to be a high suspicion of cancer.

Dr Shaf Keshavjee (Toronto, Ontario, Canada). As we try to expand the donor pool, more lungs are being used from donors with a smoking history. Would you be able to tell us how many out of the 2000 thoracic transplantations that you reported on were lung transplantations, and do you have any information on the smoking history of the donors? Finally, what is your institutional policy on the use of donors with a smoking history?

Dr Anyanwu. Of our transplantations, about 700 were lung or heart-lung transplants, and a good proportion of those were in ex-smokers. We do not consider smoking per se as a selective criteria for accepting donors, and usually, regardless of the smoking history, if other criteria are met, we use the donor lungs. Having said that, as I said earlier, none of these lungs have gone on to have cancer, and some of these lungs have gone 15 to 20 years after transplantation in our heart-lung cohort.

Dr Joseph B. Shrager (Philadelphia, $\mathrm{Pa}$ ). Congratulations on what I think is your third original presentation at this conference, which is probably some sort of a record. 
Although you suggested that epidemiologically there does not seem to be a role played by the immunosuppression in the cause of these cancers, there was, in fact, a preponderance of squamous cell carcinomas among these tumors, and this in an era when most of our bronchogenic carcinomas are adenocarcinomas. I am not a virologist, but I know there has been some suggestion that squamous cell carcinomas in some body sites are associated with certain viral infections. Because the immunosuppression that these patients receive certainly depresses cell-mediated immunity and because this might potentiate these viral infections, perhaps there is a role played by immunosupression in these cases.

Dr Anyanwu. Well, in our series I think it is just a chance finding, because 2 of the previous studies found a predominance of small cell cancers, and we found a predominance of non-small cell cancers. I think the numbers are too small, and what we are observing, we are just observing by chance. Therefore, I would not actually say there is a linkage between the cell type and immunosuppression at this stage.

\section{Authoritative}

The Journal of Thoracic and Cardiovascular Surgery is the most frequently cited thoracic/cardiovascular surgery journal in the Science Citation Index. An article in JTCVS is cited on average almost twice as often as those in the closest cardiothoracic journal. 